\title{
CONFLITOS DE USO DO SOLO EM ÁREAS DE PRESERVAÇÃO PERMANENTE NA BACIA DO RIO PIRAPORA, SALTO DE PIRAPORA/SP: INFLUÊNCIA NA QUALIDADE DAS ÁGUAS
}

\author{
Erik de Lima Andrade ${ }^{1}$ \\ Josiana Aparecida Prestes ${ }^{2}$ \\ Lidiane de Souza Vencel ${ }^{3}$ \\ Leticia Tondato Arantes ${ }^{4}$ \\ Darllan Collins da Cunha e Silva ${ }^{5}$
}

\begin{abstract}
Resumo: O objetivo desta pesquisa foi verificar a correlação entre a qualidade da água do rio Pirapora com as condições das Áreas de Preservação Permanente (APP), por meio do uso do sistema de informação geográfica e dados de sensoriamento remoto. Portanto, para a avaliação foi considerada dados do monitoramento de qualidade da água disponibilizadas pela CETESB e do uso e cobertura do solo na bacia. Para a análise dos dados, foi utilizado como referência os valores da resolução do CONAMA e técnicas estatísticas de análise multivariada. Contatou-se correlação entre parâmetros de qualidade da água e uso e cobertura do solo para o ano de 2019, enquanto para os anos anteriores a análise não retornou resultados consistentes para refutar ou confirmar as correlações. Ainda, notou-se conflitos de usos nas APP, sendo $40 \%$ das respectivas áreas sem cobertura vegetal. Por fim, alguns parâmetros de qualidade da água não atenderam aos valores de referência.
\end{abstract}

Palavras-chave: Qualidade da água, Abastecimento, Uso da terra, Monitoramento, Cobertura do solo.

\section{CONFLICTS OF LAND USE IN PERMANENT PRESERVATION AREAS IN THE PIRAPORA RIVER BASIN, SALTO DE PIRAPORA/SP: INFLUENCE ON WATER QUALITY}

Abstract: The objective of this research was to verify the correlation between the water quality of the Pirapora river with the conditions of the Permanent Preservation Areas (PPA), using a geographic information system and remote sensing data. Therefore, for the evaluation, data from the monitoring of water quality made available by CETESB and the use and coverage of the soil in the basin were considered. For data analysis,

\footnotetext{
1 Mestre em Ciências Ambientais pelo Instituto de Ciência e Tecnologia de Sorocaba - UNESP (SP). Email: eng.erik@hotmail.com

${ }^{2}$ Mestranda em Ciências Ambientais pela UNESP - Campus Sorocaba (SP). Email: josiana.ambiental@gmail.com

${ }^{3}$ Graduanda em Engenharia Ambiental pela Universidade de Sorocaba (UNISO) - Campus Sorocaba (SP). Email: vencel.lidiane@gmail.com

${ }^{4}$ Doutoranda em Ciências Ambietais pela UNESP - Campus Sorocaba (SP). Email: letondato@gmail.com

${ }^{5}$ Professor Assistente Doutor da UNESP - Campus Sorocaba (SP). Email: darllan.collins@unesp.br
} 
the values of the CONAMA resolution and statistical techniques of multivariate analysis were used as reference. A correlation was found between water quality parameters and land use and land cover for the year 2019, while for previous years the analysis did not return consistent results to refute or confirm the correlations. Still, conflicts of use in the PPA were noted, with $40 \%$ of the respective areas without vegetation cover. Finally, some water quality parameters did not meet the reference values.

Keywords: Water quality, Supply, Land use, Monitoring, Ground cover.

\section{INTRODUÇÃO}

Compreender a influência das atividades humanas a partir dos usos da terra, incluindo os aspectos de cobertura vegetal e a correlação com a qualidade da água, tem sido uma abordagem padrão utilizada no monitoramento de recursos hídricos (MWAIJENGO et al., 2020). Diversos estudos demostram que a atividade antrópica relacionada ao uso e cobertura da bacia hidrográfica impacta diretamente nos aspectos quali-quantitativos da água (ASSUNÇÃO et al., 2020), sendo a agricultura e pecuária uma das principais atividades que acarretam efeitos mais perceptíveis (ALVES et al., 2019). Ainda, de acordo com Fontana et al. (2019), a qualidade da água de rios em trechos urbanos está sujeita ações antropogênicas, decorrentes do lançamento de efluentes domésticos e industriais.

Portanto, modificações nas características e do uso e cobertura vegetal da bacia hidrográfica alteram a dinâmica e o equilíbrio dos corpos d'água e refletem, também, alterações nos parâmetros físicos, químicos e biológicos de qualidade da água, acarretando uma série de consequências (CECONELLO; CENTENO; GUEDES, 2018), tanto em termos de disponibilidade para os diversos usos nas atividades humanas, bem como para a sobrevivência das diversas formas de organismos aquáticos (CUSTODIO; PEÑALOZA, 2021).

Nesse sentido, diversas ferramentas têm sido empregadas atualmente para o monitoramento ambiental, incluindo recursos hídricos e cobertura vegetal, dentre elas destacam-se as técnicas de geoprocessamento, como o sensoriamento remoto e 0 Sistema de Informação Geográfica (SIG). De acordo com Chawla et al. (2020), o uso do sensoriamento remoto para monitoramento de recursos hídricos pode ser feito a partir da avaliação de aspectos relativos à qualidade, quantidade, mapeamento $e$ previsão de eventos extremos, possibilitando uma análise rápida e de baixo custo da dinâmica espaço-temporal envolvidas nos processos ambientais. Essa abordagem vem sendo comumente utilizada em vários trabalhos na área ambiental e foi empregada por diversos autores (GUTIERREZ et al., 2003; GUTIERREZ et al., 2017; MELLO et al., 2017; CECONELLO; CENTENO; GUEDES, 2018; XIANG et al., 2021; YIN et al, 2021; CUSTODIO; PEÑALOZA, 2021), de forma a estabelecer os efeitos das atividades antropogênicas, considerando as correlações entre parâmetros das matrizes ambientais impactadas.

Diante do exposto, nota-se a importância de compreender as características e os fatores que se interrelacionam na dinâmica do rio, visando o fornecimento de ferramentas e/ou subsídios para tomada de decisão e ações futuras, a fim de manter a qualidade e quantidade de água para o abastecimento da população.

Frente a esse cenário, o presente artigo teve como objetivo verificar a correlação entre a qualidade da água do rio Pirapora-SP com as condições das áreas 
de preservação permanente (APP) da bacia de contribuição do rio em diferentes períodos (temporal e sazonal), compreendido entre o ano de 2011 até 2019. Para tal, foi empregue dados quantitativos dos parâmetros de interesse referentes a qualidade da água, sensoriamento remoto em conjunto com o SIG e análise multivariada para o estabelecimento das correlações entre os usos nas APP e a qualidade da água.

Enfatiza-se que não foram identificados estudos que tiveram o enfoque de análise proposta, razão que motivou a sua realização, visando acrescentar novos conhecimentos sobre a evolução dos usos e ocupação na bacia delimitada e, consequentemente, seus efeitos na qualidade da água, de forma a oferecer subsídios para tomada de ações locais e, apresentação de lacunas para a realização de novos estudos.

\section{MATERIAL E MÉTODOS}

\section{ÁREA DE ESTUDO}

A bacia hidrográfica do rio Pirapora (BHRP) situa-se entre os municípios de Piedade e Salto de Pirapora, ambos localizados no estado de São Paulo. Trata-se de uma importante bacia da região metropolitana de Sorocaba (CAMPOS et al., 2016; ANDRADE, 2017), qual integra a integra a Unidade de Gerenciamento de Recursos Hídricos 10 (UGRH 10). O rio Pirapora é o principal manancial de abastecimento de ambos os municípios, sendo que para o município de Salto de Pirapora, a captação de água é realizada na região central da cidade (ANDRADE, 2017). Aproximadamente $100 \%$ da população urbana e $78 \%$ da população rural é abastecida pela água proveniente da bacia do rio Pirapora (IBGE, 2010).

Para fins de realização desse trabalho, a área de estudo foi delimitada desde a nascente até o ponto de captação de água no município de Salto de Pirapora, como pode ser verificado na Figura 1. A bacia hidrográfica delimitada possui área total de $308,55 \mathrm{~km}^{2}$.

Figura 1. Localização da bacia hidrográfica do rio Pirapora.

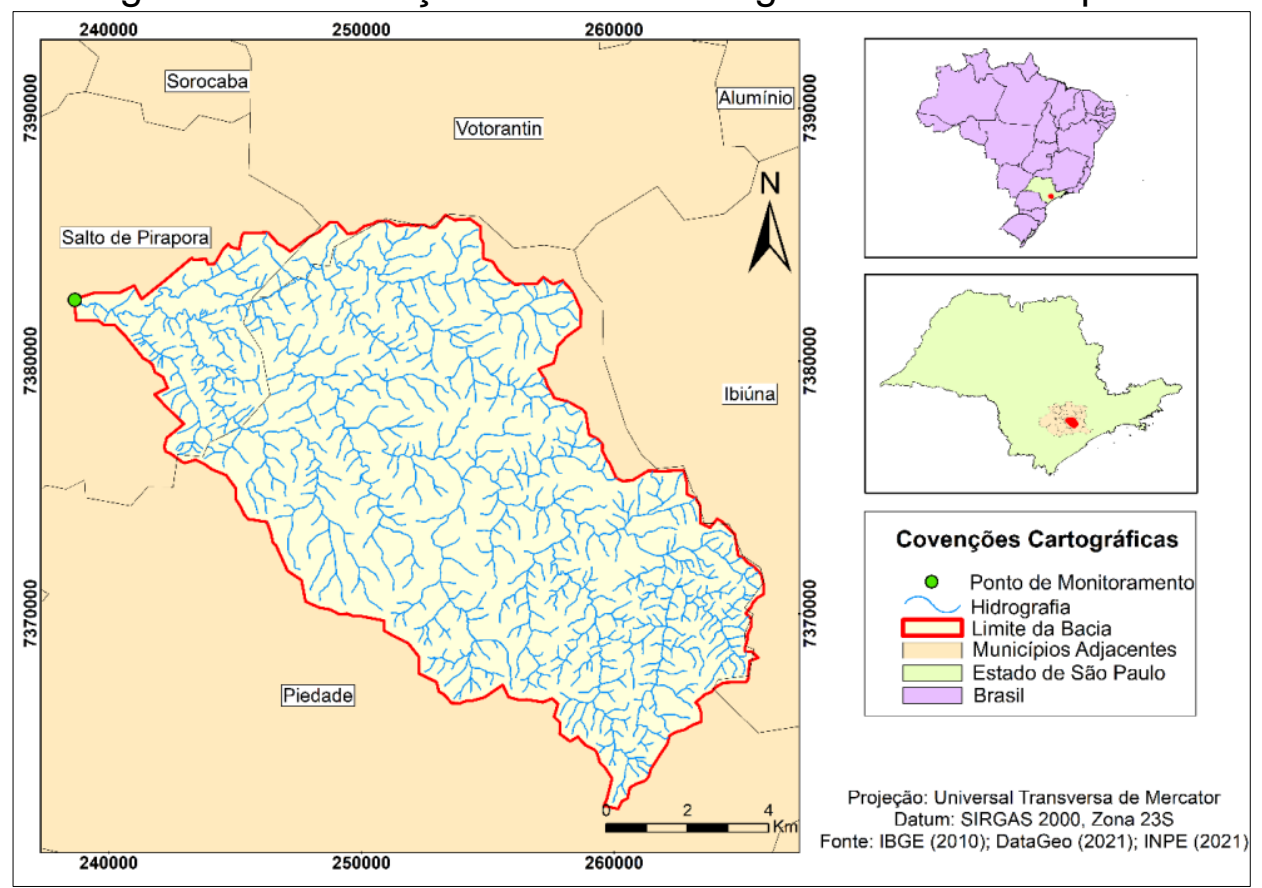

Fonte: Elaborado pelos autores, 2021. 
Os solos predominantes na bacia hidrográfica pertencem à classe dos Argissolos Vermelho-Amarelos, com textura argilosa ou média/argilosa, com fase de relevo ondulado e forte ondulado, conforme o Sistema Brasileiro de Classificação de Solos (EMBRAPA, 2006). O clima da região de acordo com o sistema de Köppen, pode ser classificado como do tipo Cwa, ou seja, temperado úmido com inverso seco e verão quente, com precipitações pluviais anuais que variam entre 1.100 e $1.700 \mathrm{~mm}$, cuja temperatura média anual é de $20^{\circ} \mathrm{C}$.

Quanto aos registros pluviométricos médio mensal da região de estudo fornecidos pelo Departamento de Água e Energia Elétrica (DAEE, 2021) de 2011 a 2019, nota-se irregularidades nas precipitações na região de estudo, sendo que o período com maior intensidade de chuva ocorre nos meses de outubro e final de março, variando entre 100 e $200 \mathrm{~mm}$, já nos meses restantes (abril a setembro) a variação média é de 40 a $100 \mathrm{~mm}$.

Conforme Silva et al. (2018), a região de Salto de Pirapora do ponto de vista geológico, está situada na faixa de transição do Planalto Atlântico para a Depressão Periférica, com presença rochas sedimentares, rochas extrusivas e intrusivas básicas pertencentes à Bacia Sedimentar do Paraná, além de rochas metamórficas e ígneas do embasamento cristalino.

\section{DELIMITAÇÃO DAS ÁREAS DE PRESERVAÇÃO PERMANENTE E QUANTIFICAÇÃO DOS USOS DO SOLO}

A bacia hidrográfica do rio Pirapora foi delimitada através dos dados do Modelo Digital de Elevação (MDE) disponibilizados pelo Instituto Nacional de Pesquisas Espaciais (INPE), por meio do projeto Topodata (INPE, 2021). A rede de drenagem do rio foi obtida por meio do MDE e possíveis inconsistências foram verificadas através de imagens do Google Earth Pro.

Para geração das APP, realizou-se um buffer de 30 metros para cada lado dos cursos d'água e um raio de 50 metros para as nascentes. Tanto para as nascentes como para o corpo d'água, a área de preservação baseou-se no disposto na lei 12.651/2012 (Código Florestal Brasileiro), que considera para rios de até 10 metros de largura, como é o caso do rio Pirapora, uma faixa de $30 \mathrm{~m}$ de APP (BRASIL, 2012).

A inserção e quantificação dos usos e ocupação do solo dentro da APP do rio foi realizada a partir de dados do MapBiomas, que disponibilizam diferentes classes já mapeadas para os diferentes biomas brasileiros (MAPBIOMAS, 2021). Neste caso, fez-se um recorte dentro das APP dos arquivos raster baixados para os anos de 2011, 2013, 2015, 2017 e 2019, referente ao bioma Mata Atlântica. Posteriormente foram identificadas e quantificadas as respectivas classes inseridas na área total da APP. O software utilizado nos processamentos foi o ArcGis 10.5.

\section{QUALIDADE DE ÁGUA DO RIO PIRAPORA}

A avalição da qualidade da água da área de estudo teve como base dados disponibilizados pela CETESB, no qual foi selecionado um único ponto de monitoramento existente na bacia hidrográfica, denominado PORA02700, localizado entre as coordenadas geográficas $23^{\circ} 36^{\prime} 53^{\prime \prime}$ Sul e 4735' 56' Oeste, próximo ao ponto de captação de água para abastecimento público do município de Salto de Pirapora (CETESB, 2021). A análise foi efetivada com base nos parâmetros de cor verdadeira, turbidez, fósforo total, nitrogênio total e $\mathrm{pH}$, para os períodos seco e chuvoso de cada ano, considerando os anos de 2011, 2013, 2015, 2017 e 2019. 


\section{ANÁLISE ESTATÍSTICA}

Inicialmente, considerando que os dados utilizados possuem medidas e escalas diferentes, com intuito de padronizá-los para assegurar pesos iguais na análise de componentes principais (ACP), realizou-se a padronização dos mesmos através da Equação 1:

$$
\mathrm{Z}=\frac{\text { Escore bruto-média }}{\text { desvio padrão }}
$$

Após padronização dos dados, procedeu-se a análise multivariada utilizando a Análise de Componentes Principais (ACP), além análise de correlação de Pearson, para os períodos seco e chuvoso, considerando estatisticamente significante dados com p<0,05 (SILVA et al., 2014). O software utilizado foi o Past versão 4.05 (HAMMER; HARPER; PAUL, 2001).

\section{RESULTADOS E DISCUSSÃO}

Enfatiza-se que, para interpretação e discussão dos resultados, considerouse a correlação existente entre uma variável de qualidade da água e uma variável de uso e ocupação do solo, de forma que, correlações entre duas variáveis de qualidade da água (por exemplo), não foram objeto de discussão, visto que esse não constituiu o objetivo do trabalho.

Porém, a interpretação dos parâmetros de qualidade da água também foi analisada a partir do seu enquadramento nos valores de referência da legislação vigente, já que esses dados, por si só, são representativos para avaliar a qualidade da água do rio.

$\mathrm{Na}$ etapa de análise estatística multivariada, a avaliação das correspondências foi baseada na representação gráfica dos resultados da ACP, uma vez que esses demonstram uma síntese dos dados quantitativos de todas as variáveis (água e cobertura do solo), sendo a significância desses também analisada a partir da matriz de correlação.

\section{MODELO DIGITAL DE ELEVAÇÃO}

O Modelo Digital de Elevação (MDE) representa as altitudes da superfície topográfica levando em consideração elementos geográficos existentes sobre ela. A partir do MDE obtido nota-se valores de elevada altitude $(1.008 \mathrm{~m})$ localizados na porção sudeste da área de estudo, que se suaviza em direção noroeste até atingir as áreas de menores altitudes (509 m), podendo observar, desta forma, que a amplitude altimétrica da região é de aproximadamente 500 metros, podendo ser considerada como de alta amplitude (COLIADO et al. 2020).

Na Figura 2 é apresentando o MDE da bacia hidrográfica do rio Pirapora, permitindo a observação da topografia do terreno. 
Figura 2. Modelo Digital de Elevação da BHRP

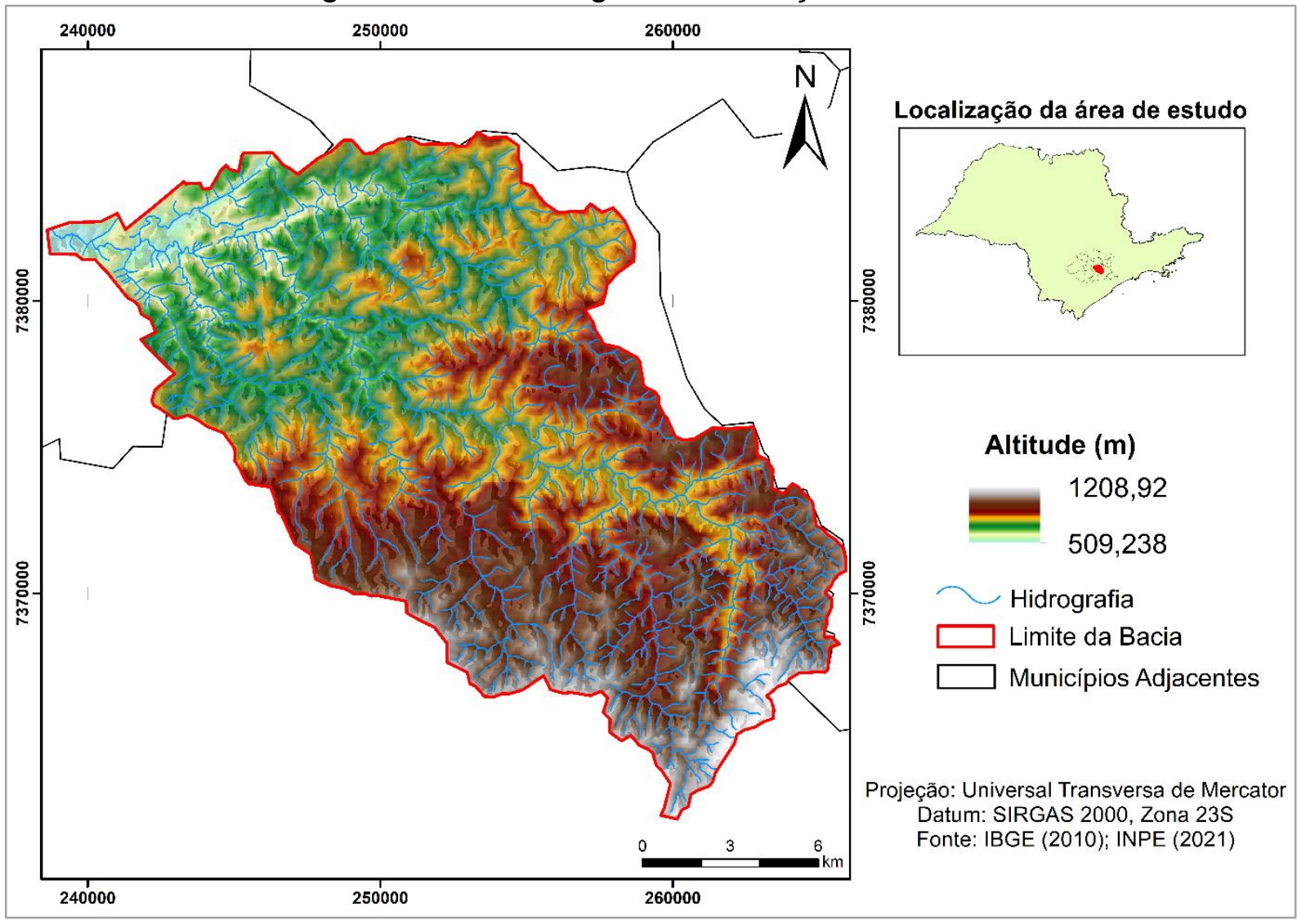

Fonte: Elaborado pelos autores, 2021.

\section{PARÂMETROS DE ÁGUA BRUTA ANALISADOS}

Ao comparar os dados brutos de qualidade da água do rio Pirapora com os valores de referência (Resolução CONAMA 357/2005), foi constatado que alguns parâmetros não atenderam o disposto na legislação. Os parâmetros cor verdadeira, fósforo total, nitrogênio total e turbidez, com exceção do $\mathrm{pH}$, se apresentaram em algum período fora do padrão de referência (Figura 3).

A não conformidade é mais recorrente no período chuvoso, o que pode ser explicado pela lixiviação e carreamento de materiais e outros compostos para o corpo d 'água. Elevados valores de nitrogênio total e fósforo total, são frequentemente associados aos usos na agricultura, derivados da formulação de fertilizantes, que de acordo com Mello et al. (2018), se acumulam em solos agrícolas. Em um estudo realizado por Schneider e Costa (2013) em uma microbacia do rio Pirapora, foi constatado que $96 \%$ dos agricultores que participaram do estudo utilizam fertilizantes industrializados com elevada concentração e solubilidade de N-P-K em seus agroecossistemas. Altas concentrações de nitrogênio e fósforo também podem estar relacionados a despejos de efluentes industriais e domésticos, uma vez que essa bacia possui usos múltiplos outorgados (ANDRADE, 2017), o que pode explicar as concentrações acima do limite estabelecido para o parâmetro fósforo, também no período seco. Quanto aos parâmetros turbidez e cor verdadeira, esses ultrapassaram os valores de referência permitidos na norma somente no período chuvoso. Tal fato pode estar associado as partículas em suspensão decorrente de chuvas devido a presença de áreas de agricultura e conflitos de uso do solo em APP (SIMONETTI; SILVA; ROSA, 2019). 
Os resultados obtidos para os cinco parâmetros de qualidade da água do rio Pirapora (período seco e período chuvoso), extraídos a partir do ponto de monitoramento da CETESB, são apresentados na Figura 3.

Figura 3. Valores dos parâmetros de qualidade da água nos anos amostrados
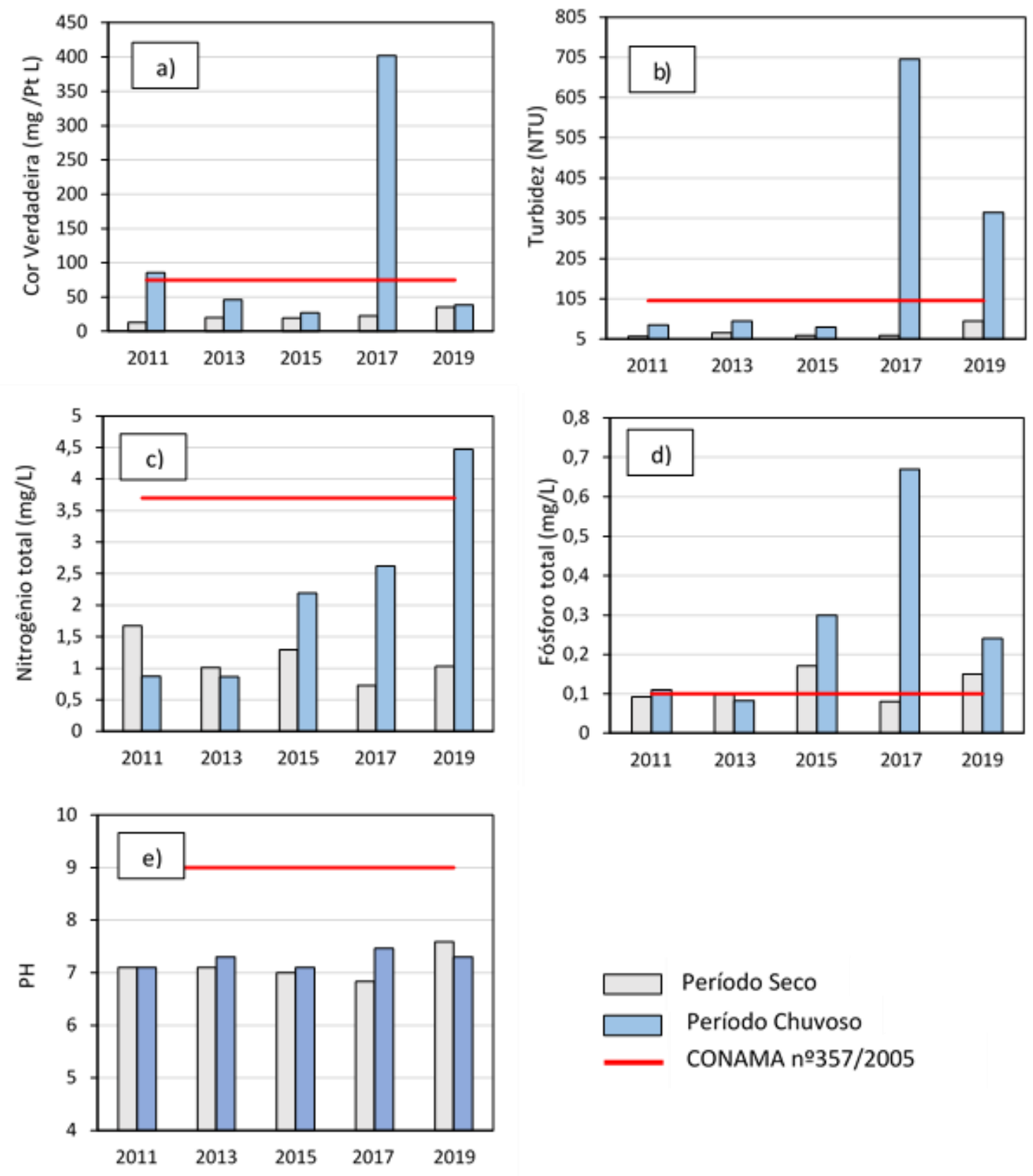

Fonte: Elaborado pelos autores, 2021.

\section{USOS EXISTENTES NA BACIA E A COBERTURA VEGETAL DAS APP}

Quanto aos usos e ocupações na área da bacia delimitada, foram identificados 9 tipos de uso, com base nas classes já mapeadas pelo MapBiomas. Os tipos de uso identificados foram Agricultura e Pastagem (AP), Infraestrutura Urbana (IU), Formação Florestal (FF), Pastagem (P), Floresta Plantada (FP), Mineração (M), Corpos d'Água (CA), Outras Lavouras Temporárias (OLT) e Outras Áreas Não Vegetadas (OANV) (Figura 4). 
Figura 4. Mapas de uso e cobertura do solo e APP

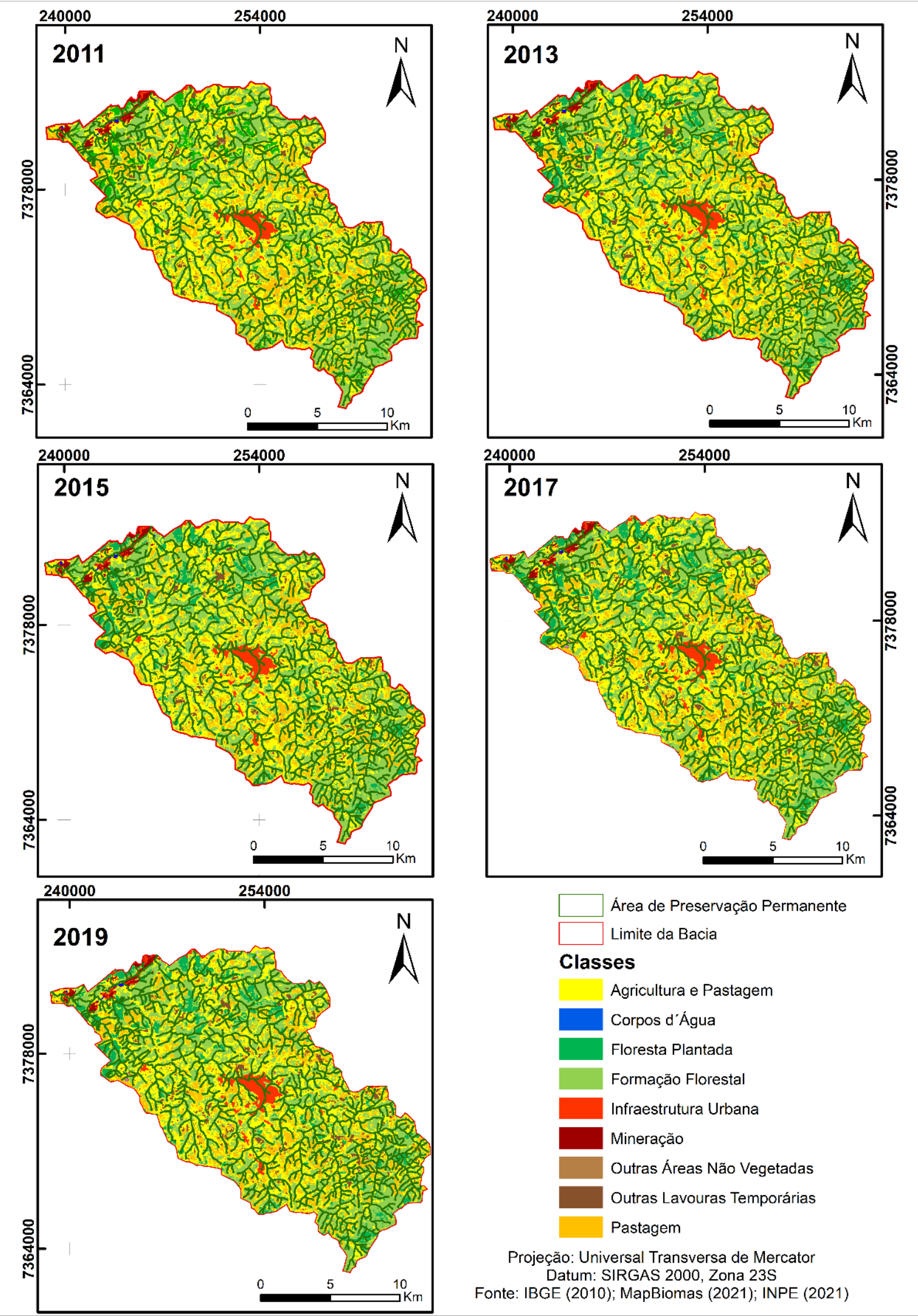

Fonte: Elaborado pelos autores, 2021.

Verificou-se que, no período de 2011 a 2019, não houve alteração significativa nas taxas de cobertura vegetal das APP (Figura 5) (considerando floresta plantada e 
formação florestal), sendo que a variação entre essas duas condições (área com cobertura vegetal e área sem cobertura vegetal) se deu em torno de $2 \%$. Sobre esses valores, podemos inferir que há um conflito evidente na ocupação das APP com relação às premissas de preservação ambiental, onde a porcentagem total de área com usos conflitantes chega a $40 \%$, de uma área total correspondente a $41,45 \mathrm{~km}^{2}$. O trabalho de Pires et al. (2016) também corrobora com essa constatação, ao concluir que somente $58,06 \%$ da área das APP existentes no município é referente a usos não conflitantes.

Dentre os usos identificados, são destacados os mais representativos, onde verifica-se uma maior taxa de cobertura do solo por formação florestal, seguido por agricultura e pastagem. É expressivo também a participação de usos passíveis de causarem alteração na qualidade ambiental nas matrizes de solo e água, identificados como, infraestrutura urbana e mineração. O número de classes identificadas para esse trabalho é próximo ao número de classes identificadas por Marzola et al. (2019), que identificaram 13 padrões de uso do solo ao longo do perfil longitudinal do rio Pirapora, sendo mineração e silvicultura os padrões mais relevantes e que tiveram maior correlação em algumas das sub-bacias estudadas pelos autores, que visavam a identificação de metais nas águas do rio, associados a fontes de contaminação e padrões de uso e ocupação do solo.

Figura 5. Identificação e quantificação dos usos do solo nas APP da bacia hidrográfica do rio Pirapora

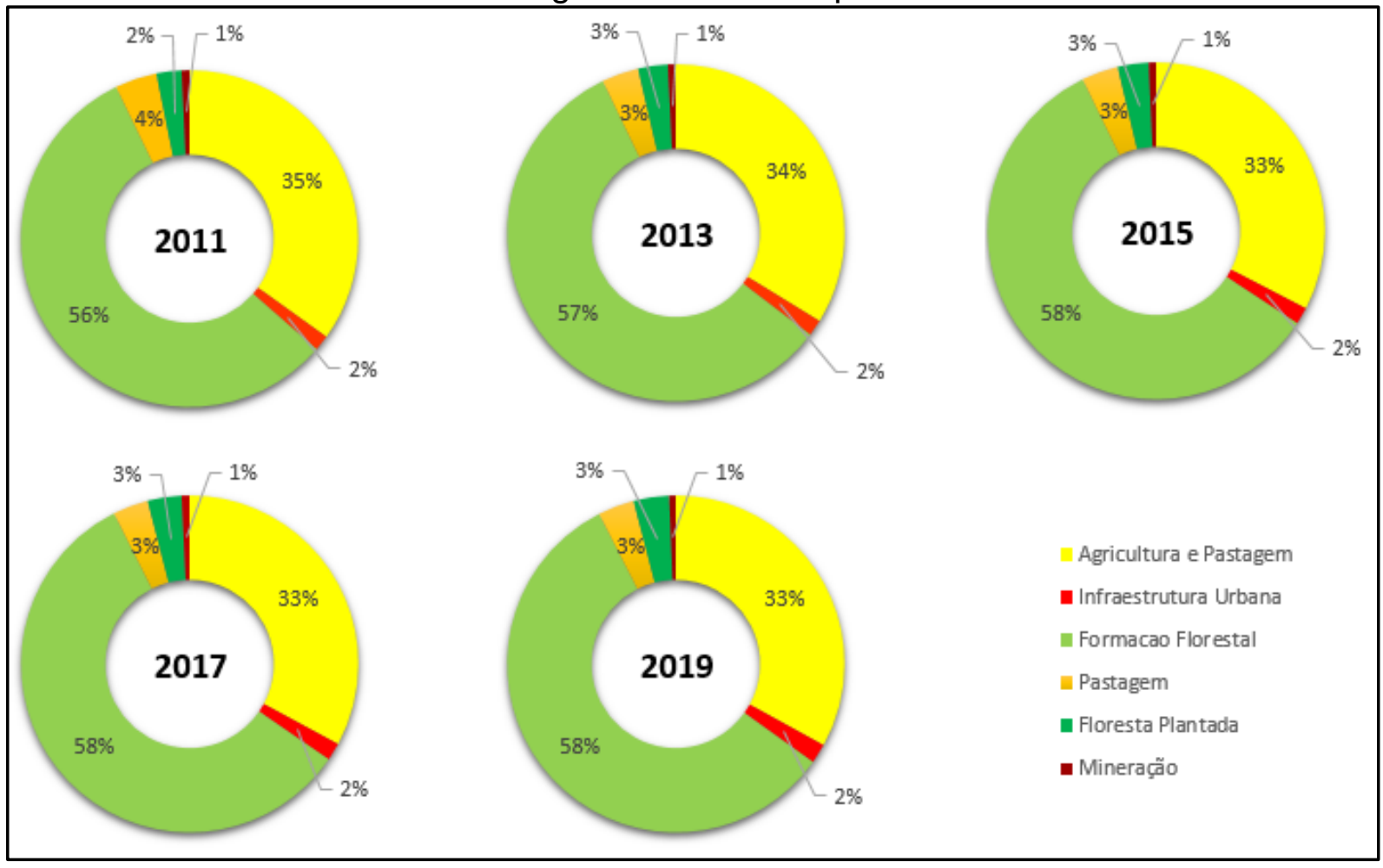

Fonte: Elaborado pelos autores, 2021. 

QUALIDADE DA ÁGUA E USO E COBERTURA DO SOLO

Realizou-se a análise de ACP com o objetivo de verificar quais parâmetros possuíam correspondências e maior representatividade no conjunto de amostras. Verificou-se que a primeira componente (PC1) gerada para cada um dos períodos (seco e chuvoso), explicaram em torno de $60 \%$ da variância, respectivamente.

Para a definição e escolha das componentes principais, não há uma regra absoluta a ser seguida, porém, a observação de variações abruptas na quantidade de variância explicada por cada PC pode ser um critério de escolha, assim como a interpretação química e/ou física de seus significados (VALDERRAM; PAIVA; MARÇO, 2016). Componentes que explicam $60 \%$ da variância acumulada são suficientes para representar a variância original (HAIR JÚNIOR et al., 2007; ROCHA; PEREIRA, 2016), assim, adotou-se para esse trabalho a primeira componente calculada para cada um dos períodos. Na Figura 6, é apresentada o resultado da PC1 para o período seco.

Figura 6. Representação gráfica da análise ACP no período seco

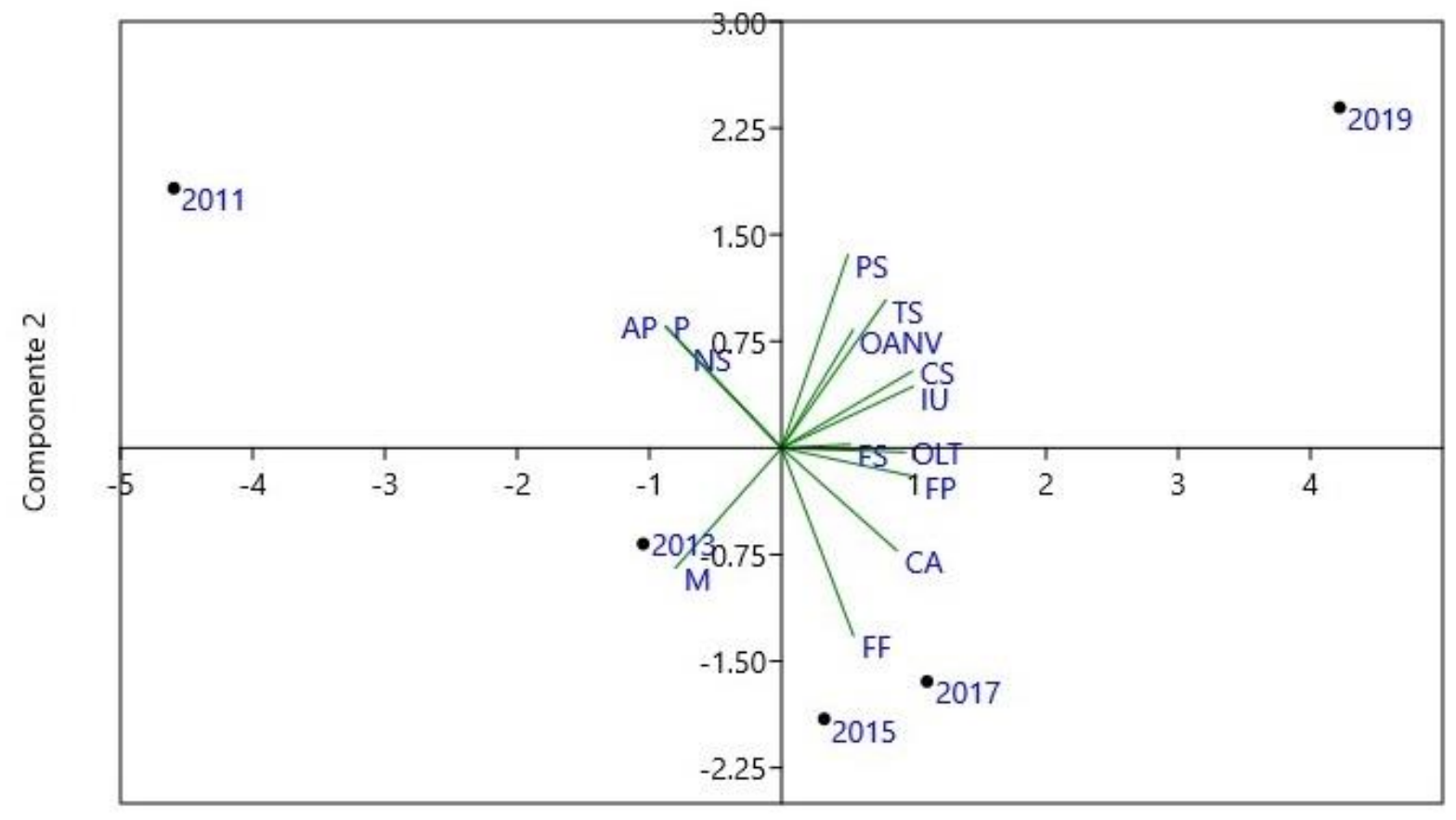

Componente 1

Legenda: $\mathrm{PS}=\mathrm{pH}$ período seco; TS = turbidez período seco; FS = fósforo total período seco; $\mathrm{NS}=$ nitrogênio total período seco; $C S=$ cor verdadeira período seco.

Fonte: Elaborado pelos autores, 2021.

Verificou-se então, no conjunto de variáveis da ACP, que nos anos de 2011, 2013, 2015 e 2017, não foi demonstrado nenhuma correspondência entre variáveis de qualidade da água e variáveis de uso e ocupação do solo, em ambos os períodos. Uma correspondência entre parâmetros de qualidade da água e de uso e ocupação do solo foi observada no ano de 2019, tanto para o período seco como para o período chuvoso.

Para o período seco, a infraestrutura urbana teve correspondência significativa com os parâmetros $\mathrm{pH}$, turbidez e cor verdadeira, podendo inferir que a 
área urbana pode estar influindo sobre os valores dos parâmetros de turbidez e cor verdadeira encontrados, uma vez que a área urbana do município do Salto de Pirapora está próxima ao ponto de monitoramento, possuindo fontes importantes que originam a elevação da turbidez da água, ainda, as ações antropogênicas, principalmente, nas áreas de APP ou em proximidade a elas podem contribuir com o aumento dos materiais sólidos em suspensão nos corpos d'água. No estudo de Andrade et al. (2007), observou-se uma inter-relação entre cor, turbidez, sólidos suspensos e o pH, apresentando-se como um fator de transporte de sedimentos. Levando em consideração a proximidade com área urbana, Fontana et al. (2019) observaram que valores mais altos para os parâmetros cor e turbidez no período seco estariam associados a alguma atividade antrópica, como descargas de efluentes próximo, ainda, segundo Carvalho e Siqueira (2011) valores de turbidez tendem a aumentar onde há maior concentração populacional e industrial. Quanto ao pH, apesar de ter demonstrado uma correspondência com IU, de acordo com os dados de monitoramento de qualidade de água apresentados na Figura 2, esse parâmetro não teve variação significativa ao longo dos anos e dos períodos avaliados (Figura 7).

Figura 7. Representação gráfica da análise ACP no período chuvoso

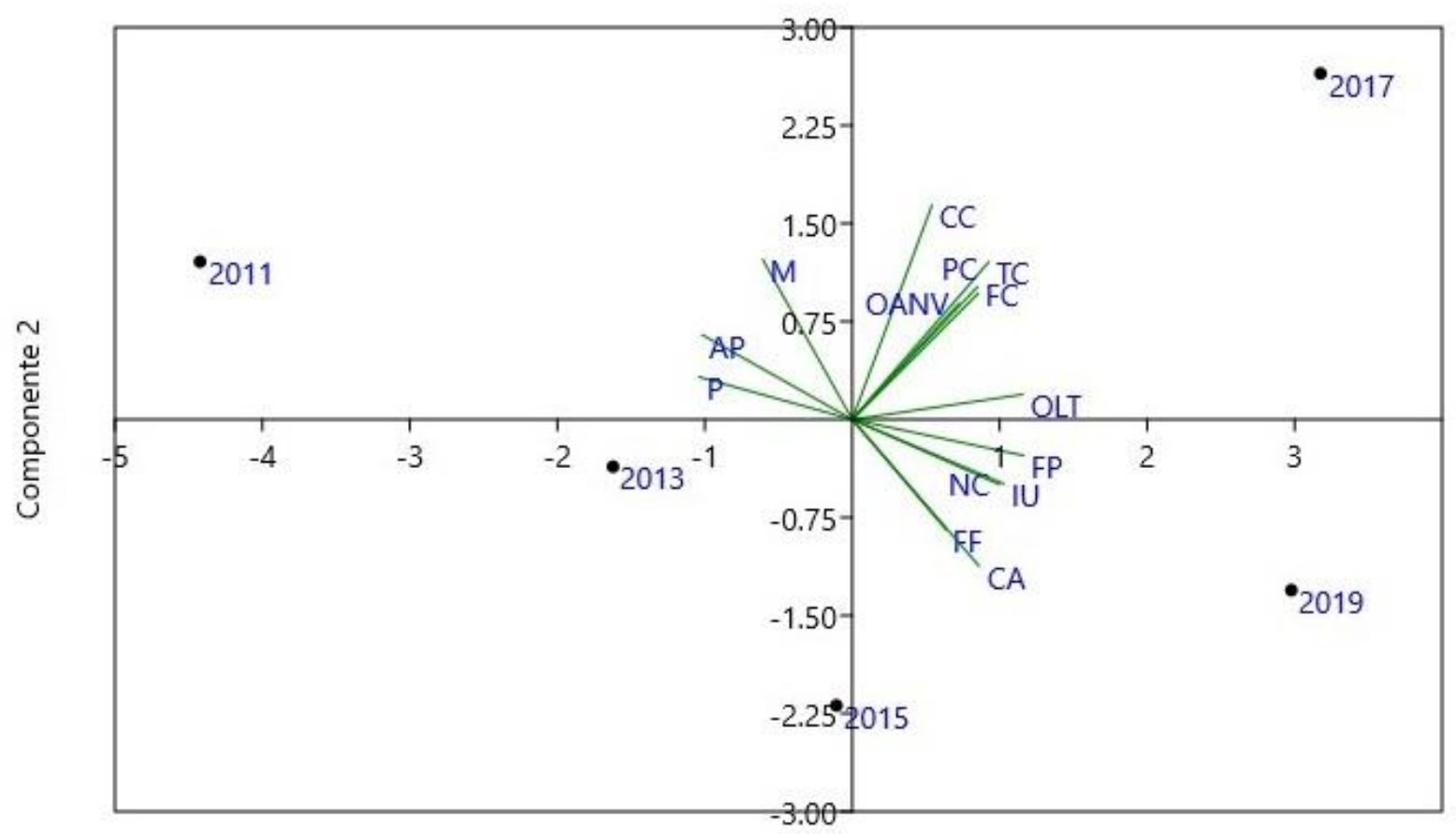

Componente 1

Legenda: $\mathrm{PC}=\mathrm{pH}$ período chuvoso; $\mathrm{TC}=$ turbidez período chuvoso; $\mathrm{FC}=$ fósforo total período chuvoso; $\mathrm{NC}=$ nitrogênio total período chuvoso; $\mathrm{CC}=$ cor verdadeira período chuvoso.

Fonte: Elaborado pelos autores, 2021

Para o período chuvoso, a relação mais forte verificada foi entre IU e nitrogênio total. Pode-se inferir que essa correspondência entre as variáveis, para o período chuvoso, deve-se ao fato do ponto de monitoramento que gerou os dados utilizados neste trabalho, encontrar-se nas proximidades do centro urbano. De acordo com Finkler et al. (2016), foi observado pela análise de ACP que o nitrogênio teve forte influência na qualidade da água em bacias hidrográficas do município de Caxias do Sul-RS, associados ao despejo de efluentes de origem doméstica e industrial in 
natura. Assim, essa concentração nos valores de nitrogênio pode estar associada ao lançamento de esgotos próximo ao ponto de monitoramento. Dentro do escopo de avaliação do trabalho, a fim de verificar se houve concordância com os resultados obtidos pela ACP, aplicou-se também uma análise de correlação de Pearson, para os dados de ambos os períodos. Os resultados dessa análise de correlação são apresentados nas Figuras 8 e 9.

Figura 8. Matriz de correlação de Pearson para o período seco

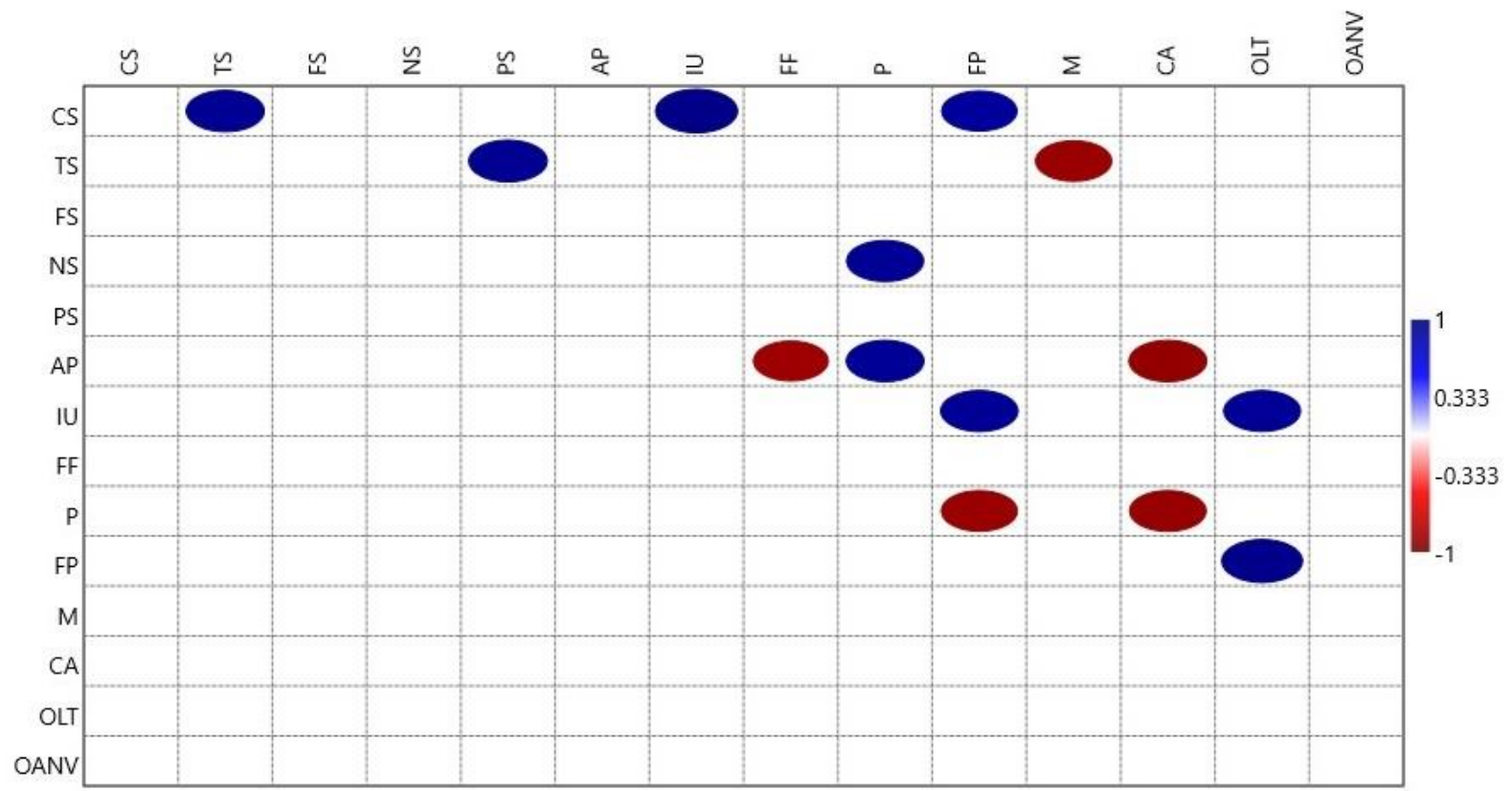

Legenda: $\mathrm{PS}=\mathrm{pH}$ período seco; TS = turbidez período seco; FS = fósforo total período seco; NS = nitrogênio total período seco; $C S$ = cor verdadeira período seco.

Fonte: Elaborado pelos autores, 2021

Figura 9. Matriz de correlação de Pearson para o período chuvoso

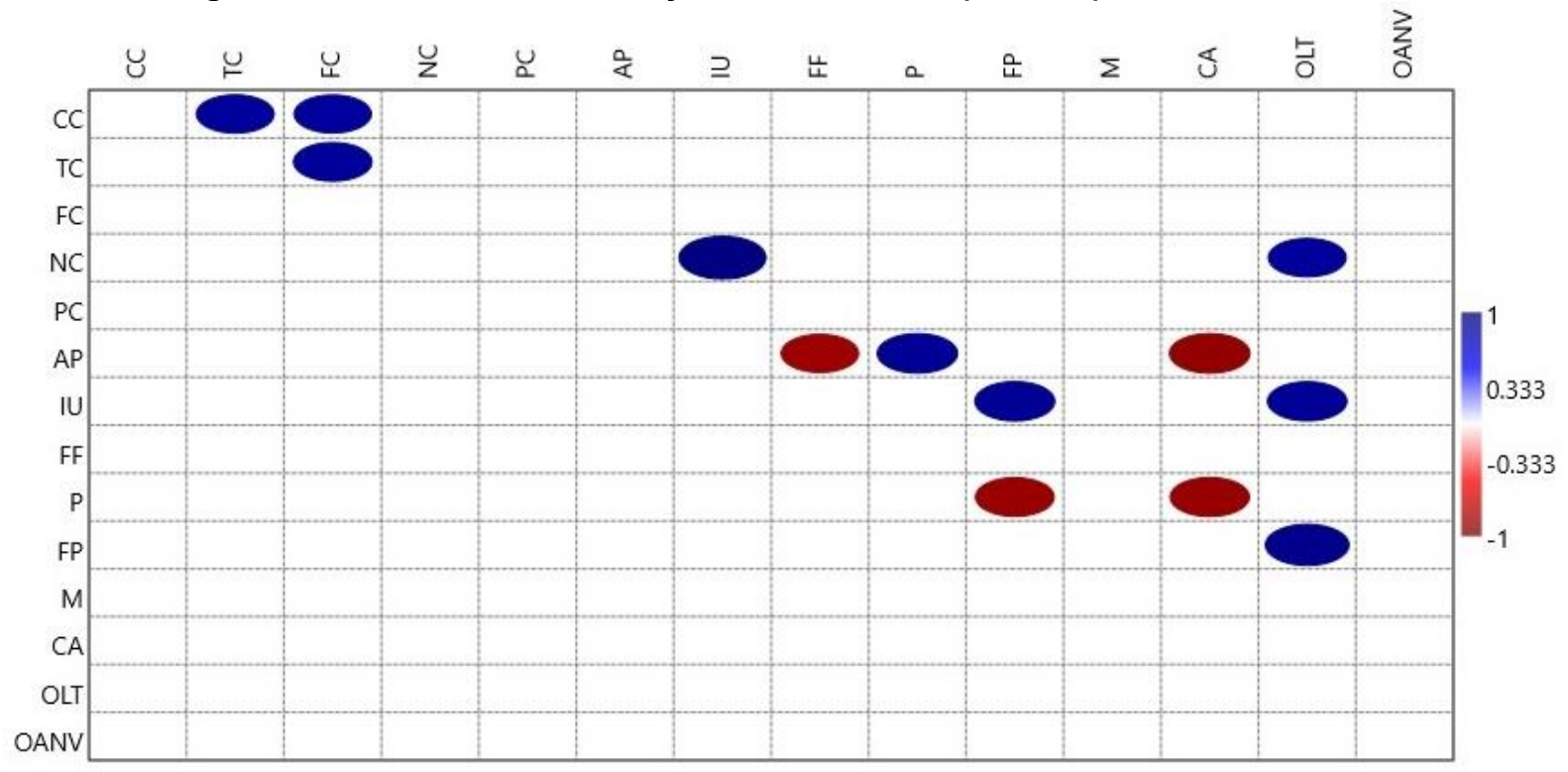

Legenda: $\mathrm{PC}=\mathrm{pH}$ período chuvoso; $\mathrm{TC}=$ turbidez período chuvoso; $\mathrm{FC}=$ fósforo total período chuvoso; $\mathrm{NC}=$ nitrogênio total período chuvoso; $\mathrm{CC}=$ cor verdadeira período chuvoso.

Fonte: Elaborado pelos autores, 2021 
Para a interpretação das Figuras 8 e 9, salienta-se que foram desconsideradas correlações entre variáveis do mesmo tipo (cor verdadeira e turbidez, por exemplo), atendo-se a correlação existente entre uma variável de qualidade da água $x$ variável de uso do solo.

Dessa forma, no período seco houve forte correlação entre cor verdadeira e IU $(r=0,96 ; p<0,05)$, dados que tiveram correspondência também na análise de ACP. Também houve correlação entre cor verdadeira e FP $(r=0,88 ; p<0,05)$ e entre nitrogênio e $P(r=0,91 ; p<0,05)$. Ainda que não tenham tido correspondências na análise de $A C P$, observa-se que, no caso de nitrogênio e $P$, essa correlação pode estar associada a possíveis adubações nitrogenadas no manejo dessa atividade, levando-se em consideração as taxas desse tipo de uso situadas acima de $30 \%$ na APP em todos os anos observados. Porém, acrescenta-se a essa observação, de acordo com Primavesi et al. (2006), que o uso de nitrogênio em pastagens, quando bem manejadas, parece não ser impactante quanto às perdas por lixiviação, em situações em que esse elemento é absorvido pelas plantas e quando o lençol freático não é superficial.

Fatores como o tipo de solo (arenoso ou argiloso), e volume de lâmina de água incidente sobre o solo também influenciam na lixiviação, conforme observado por Mendes et al. (2015). A correlação entre cor verdadeira e FP, ainda que esse tipo de uso (FP) represente uma taxa pequena nas APP, essa relação pode estar associada a atividades de manutenção em áreas de silvicultura (por exemplo), que exigem manejo periódico de condução, como pode ser observado na Figura 10.

Figura 10. Áreas de APPs com a presença da classe de Floresta Plantada (FP)

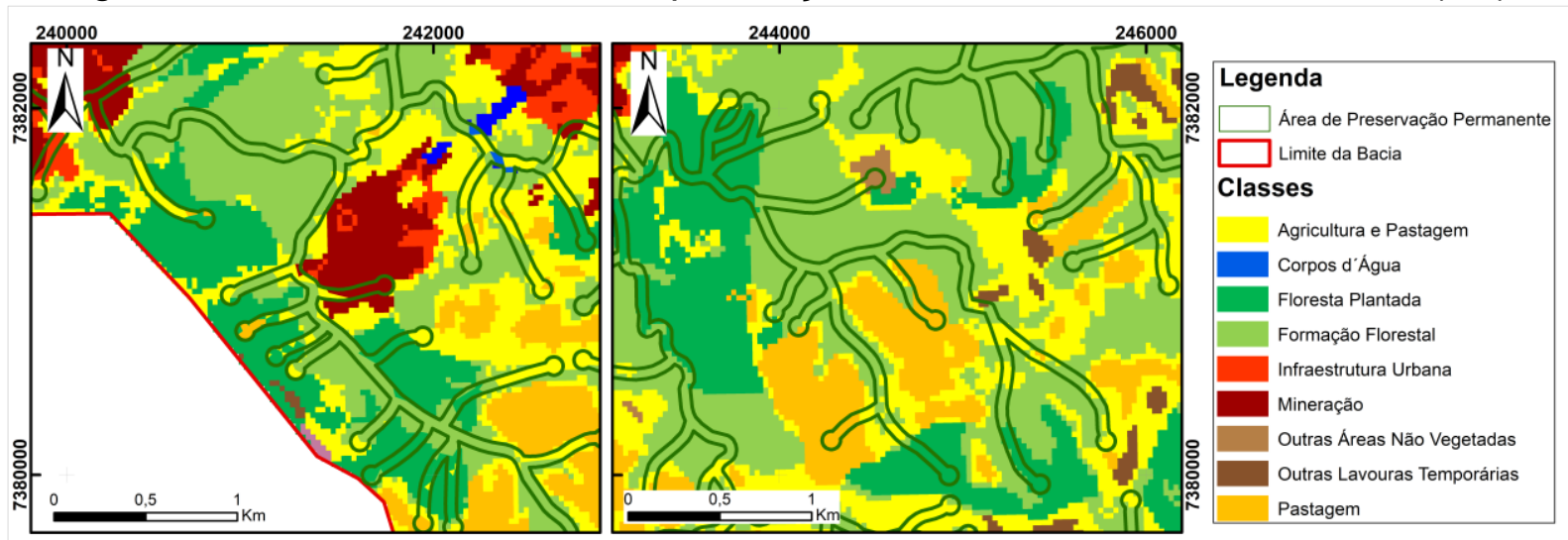

Fonte: Elaborado pelos autores, 2021

Ainda, Cor verdadeira apresenta ainda correlação com turbidez (correlação esperada) e IU. Sobre a correlação com IU, uma vez admitido a possibilidade de haver despejos de esgoto nas proximidades do ponto de monitoramento, essa correlação é também justificada.

Por fim, levando em consideração o período chuvoso nota-se que houve forte correlação entre nitrogênio total e IU $(r=0,99 ; p<0,05)$, em concordância com a ACP do mesmo período. Essa correlação pode estar associada com o lançamento de esgotamento sanitários e efluentes industriais na área de estudo, sendo estas uma das principais fonte de nitrogênio.

Ressalta-se que a ocupação do solo influencia diretamente nas condições na qualidade da água, conforme relatado por Silva et al. (2017) em seus estudos e que as condições socioeconômicas das populações vulneráveis que vivem no entorno de cursos de água também exercem influência direta sobre os corpos de água podendo 
comprometer sua qualidade e quantidade (SALES et al., 2019). Desta forma, sugerese novos estudos e pontos de monitoramento ao longo da bacia visando retratar de forma mais setorial os diversos compartimentos e particularidades presentes na bacia, possibilitando, desta forma, obter um diagnóstico mais incisivo a cerca dos possíveis impactos que vem ocorrendo na bacia e sua extensão territorial.

\section{CONCLUSÕES}

Dentro da hipótese que norteou a realização desse artigo, apesar de, a priori a literatura ter demonstrado em outros trabalhos correlações existentes entre a qualidade da água e o uso e ocupação do solo, os resultados obtidos neste estudo não demonstraram uma correspondência representativa, apesar que para o ano de 2019, essa correspondência tenha sido observada para a variável de infraestrutura urbana. Ainda que não tenha sido possível estabelecer correspondências mais conclusivas entre usos do solo e qualidade da água, tomando-se como referência o ponto de monitoramento dos dados e sua localização geográfica em relação a área urbana, em uma perspectiva mais atual (considerando também a temporalidade), é significativo que a IU seja a variável que tenha se sobressaído na análise de ACP.

Considerando que o ponto de monitoramento está próximo ao ponto de captação de água do município, faz-se necessário uma atenção maior do poder público quanto às atividades que estão sendo desenvolvidas nessa área, que podem, no decorrer do tempo, ter um impacto cada vez maior sobre a qualidade da água do rio nesse ponto. Essa preocupação é também justificada ao se analisar os dados brutos do ponto de monitoramento, que demonstram uma recorrência de não conformidade dos valores de referência na legislação, especialmente dos parâmetros nitrogênio total e fósforo total, que podem ser reflexo de outras atividades identificadas na bacia (agricultura, por exemplo), como também, considerando a correspondência com IU, estar associados a despejos sanitários nas águas do rio.

A recomposição das APP é outro fator que deve ser levado em consideração pela gestão pública, visto que a porcentagem de cobertura vegetal das APP levantada neste trabalho, sinaliza uma situação de conflito de usos, com cerca de $40 \%$ das APP desprovidas de cobertura vegetal.

Como limitações para o alcance de resultados mais precisos, um dos fatores a ser citado é a questão da resolução espacial das imagens de satélite utilizadas, as quais foram obtidas pelo projeto MapBiomas. Essa base de dados gratuita utiliza imageamento da série Landasat, que apresenta uma resolução espacial de $30 \mathrm{~m}$ por pixel. Considerando que a faixa de APP do rio em questão também é de $30 \mathrm{~m}$, pode ocorrer a situação em que objetos menores, que porventura estejam locados na APP não sejam detectados na imagem (uma pequena edificação, por exemplo).

Cita-se ainda a questão das limitações impostas aos estudos elaborados a partir de banco de dados públicos, como foi o caso do trabalho em questão, no qual se contou apenas com os dados referentes a um ponto de monitoramento, em toda a extensão do rio inserida dentro do município de interesse. Tal fato nos permite inferir uma deficiência na questão de monitoramento pela gestão pública, em termos de abrangência territorial.

Para o alcance de resultados mais abrangentes em trabalhos futuros, com o mesmo enfoque proposto nesse artigo, recomenda-se a utilização de imagens com uma resolução espacial maior (já disponibilizado por séries de satélites como 0 CBERS-04A, por exemplo), e com uma rede de pontos de monitoramentos que abranjam uma extensão maior do rio inserida dentro da bacia delimitada. Também, 
considerando que alguns parâmetros não atenderam os limites estabelecidos na legislação, dando um indicativo do lançamento de esgotos próximo ao ponto de captação, seria recomendável, em um estudo futuro acrescentar na análise de qualidade de água, outras formas de nitrogênio, que poderiam confirmar essa hipótese.

\section{REFERÊNCIAS BIBLIOGRÁFICAS}

ALVES, W. D. S. et al. Análise das relações entre uso do solo e qualidade da água do Lago Bonsucesso, em Jataí, Estado de Goiás, Brasil. Revista Brasileira de Geografia Física, v. 12, n.1, p. 326-342, 15 jan. 2019. doi:10.26848/rbgf.v12.1.p326342

ANDRADE, E. D. L. Análise de eficiência de biopolímero como composto coadjuvante no processo de coagulação-floculação e sedimentação. 2017. 91 p. Dissertação (Mestrado em Ciências Ambientais) - Universidade Estadual Paulista UNESP, Campus Sorocaba., Sorocaba, 2017.

ANDRADE, E. M. D. et al. Fatores determinantes da qualidade das águas superficiais na bacia do Alto Acaraú, Ceará, Brasil. Cienc. Rural, Santa Maria, v.37, n.6, p. 1791 1797, dez. 2007. doi:10.1590/S0103-84782007000600045

ASSUNÇÃO, E. G. et al. Análise temporal do uso e cobertura do solo e da qualidade da água da Bacia Hidrográfica do rio Tibagi. Revista DAE, v.68, n.222, p. 121-133, mar 2020. doi: 10.36659 /dae.2020.020

BRASIL, Lei 12.651 de 25 de maio de 2012. Código Florestal Brasileiro. Disponível em: http://www.planalto.gov.br/ccivil_03/_ato2011-2014/2012/lei//12651.htm. Acesso em: 15 mar de 2021.

BRASIL. Departamento Nacional de Águas e Energia Elétrica. Banco de dados hidrológicos. DNAEE, 2021. Disponível: http://www.hidrologia.daee.sp.gov.br/. Acesso em: 27 mar de 2021.

BRASIL. MINISTÉRIO DO MEIO AMBIENTE. CONSELHO NACIONAL DO MEIO AMBIENTE. Resolução $\mathrm{n}$ ㅇ 357, 17 de março de 2005. Dispõe sobre a classificação dos corpos de água e diretrizes ambientais para o seu enquadramento, bem como estabelece as condições e padrões de lançamento de efluentes, e dá outras providências. Diário Oficial da União, Brasília, 2005. Disponível em: http://www2.mma.gov.br/port/conama/legiabre.cfm?codlegi=459. Acesso em: 15 mar 2021.

CAMPOS, V. et al. Physicochemical characterization and evaluation of PGA bioflocculant in coagulation-flocculation and sedimentation processes. Journal of Environmental Chemical Engineering, v.4, p. 3753-3760, dez 2016. doi: 10.1016/j.jece.2016.08.011

CARVAlHo, G. L.; SIQUEIRA, E. Q. Qualidade da Água Do Rio Meia Ponte no Perímetro Urbano do Município de Goiânia - Goiás. REEC - Revista Eletrônica De Engenharia Civil, v.2, n.1, 2011. doi: https://doi.org/10.5216/reec.v2i1.12293 
CECONELLO, S. T.; CENTENO, L. N.; GUEDES, H. A. S. Índice de qualidade de água modificado pela análise multivariada: estudo de caso do Arroio Pelotas, RS, Brasil. Engenharia Sanitária e Ambiental, v. 23, n. 5, p.973-978, out. 2018. doi: 10.1590/s1413-41522018165394

CETESB - COMPANHIA DE TECNOLOGIA DE SANEAMENTO AMBIENTAL. Sistema de Informação InfoAGUAS. Disponível em: https://cetesb.sp.gov.br/infoaguas/. Acesso em: 15 mar de 2021.

CHAWLA, I.; KARTHIKEYAN, L.; MISHRA, A. K. A review of remote sensing applications for water security: Quantity, quality, and extremes. Journal of Hydrology, v.585, p. 1-28, 2020. doi: 10.1016/j.jhydrol.2020.124826

COLIADO, P. H. S.; SIMONETTI, V. C.; SILVA, D. C. C. Avaliação das características físicas da bacia hidrográfica do rio Pariquera-Açu no Baixo Ribeira de Iguape (SP). Holos Environment, v. 20, p. 320-334, 2020. doi: https://doi.org/10.14295/holos.v20i3.12386

COSTA, D. R. et al. Diagnóstico Sócio-econômico e percepção ambiental na microbacia do rio Pirapora, Piedade-SP. Revista Científica Eletrônica de Engenharia Florestal, v.18, p. 22-34, 2011.

CUSTODIO, M.; PEÑALOZA, R. Data on the spatial and temporal variability of physical-chemical water quality indicators of the Cunas River, Peru. Chemical Data Collections, v.33, p. 1-14, 2021. doi: 10.1016/j.cdc.2021.100672.

EMPRESA BRASILEIRA DE PESQUISA AGROPECUÁRIA - EMBRAPA. Centro Nacional de Pesquisa de Solos. Sistema brasileiro de classificação de solos. 2.ed. Rio de Janeiro, 2006. 306p.

FINKLER, N. R. et al. Avaliação espaço-temporal da qualidade da água utilizando técnicas estatísticas multivariadas. Ciência e Natura, v.38 n.2, p. 577-587, 2016. doi: $10.5902 / 2179-460 \times 18168$

FONTANA, A. C. D. et al. Investigação ambiental de indicativos de qualidade da água em trechos dos rios urbanos em Lucaia e Jaguaribe em salvador, Bahia, Brasil. Revista de Gestão de Água da América Latina, v.16 n.8, p. 1-13, 2019. doi: 10.21168/rega.v16e8

GUTIÉRREZ, M.; JOHNSON, E.; MICKUS, K. Watershed assessment along a segment of the Rio Conchos in Northern Mexico using satellite images. Journal of Arid Environments, v.56, p. 395-412, 2003. doi: 10.1016/S0140-1963(03)00060-0

GUTIERREZ, C. B. B. et al. Análise espaço-temporal do uso e cobertura do solo no interior da APA Belém e correlação com os parâmetros de água dos seus mananciais. Revista Brasileira de Geografia Física, v.10, n.01, p. 521-534, 2017. doi: 10.5935/1984-2295.20170033 
HAMMER, O.; HARPER, D. A. T.; PAUL, D. R. Past: Paleontological Statistics Software Package for Education and Data Analysis. Palaeontologia Electronica, v.4, n.1, p. 1-9, 2001.

HAIR JUNIOR., J. F. et al. Análise multivariada de dados. 5. ed. Bookman, 2007.

Instituto Brasileiro de Geografia e Estatística - IBGE. Abastecimento de Água (2010). Disponível em: https://infosanbas.org.br/municipio/salto-de-pirapora-sp/. Acesso em: 16 mar de 2021.

MARZOLA, E. L. et al. Spatial modeling applied to environmental monitoring: identifying sources of potentially toxic metals in aquatic system. Environ Geochem Health, v.41, p. 1339-1350, 2019.doi:10.1007/s10653-018-0218-5

MAPBIOMAS - Coleção Mata Atlântica. Disponível em https://mapbiomas.org/. Acesso em: 15 mar de 2021.

MENDES, W. D. C.; et al. Lixiviação de nitrato em função de lâminas de irrigação em solos argiloso e arenoso. IRRIGA \& INOVAGRI, v.1, n.2, p. 47-56, 2015. doi: 10.15809/irriga.2015v1n2p47

MELLO, K. D. et al. Riparian restoration for protecting water quality in tropical agricultural watersheds. Ecological Engineering, v.108, p. 514-524, 2017. doi:https://doi.org/10.1016/j.ecoleng.2017.06.049

MELLO, K. D. et al. Impacts of tropical forest cover on water quality in agricultural watersheds in southeastern Brazil. Ecological Indicators, v. 93, p. 1293-1301, 2018. doi:10.1016/j.ecolind.2018.06.030

MWAIJENGO, G. N. et al. Where does land use matter most? Contrasting land use effects on river quality at different spatial scales. Science of the Total Environment, v.715, p. 1-13, 2020. doi:10.1016/j.scitotenv.2019.134825

PIRES, V. R. D. O. P. et al. Identificação de conflito de uso da terra em Áreas de Preservação Permanente no município de Salto de Pirapora, SP. Ambiência, v.12 n.20, p. 953 - 962, 2016. doi: 10.5935/ambiencia.2016.Especial.20

PRIMAVESI, O. et al. Lixiviação de nitrato em pastagem de coastcross adubada com nitrogênio. Revista Brasileira de Zootecnia, v.35, n.3, p. 683-693, 2006. doi:10.1590/S1516-35982006000300008

ROCHA, C. H. B.; PEREIRA, A. M. Análise multivariada para seleção de parâmetros de monitoramento em manancial de Juiz de Fora, Minas Gerais. Revista Ambiente \& Água, v.16, n.1, p. 176-187, 2016.doi: 10.4136/ambi-agua.1590

RODRIGUES, E. R. Cidades da região de Sorocaba também enfrentam problemas com a estiagem. Jornal Cruzeiro do Sul, 18 set. 2020. Disponível em: https://www.jornalcruzeiro.com.br/sorocaba/cidades-da-rms-tambem-enfrentamproblemas-com-a-estiagem-e-moradores-com-falta-de-agual. Acesso em: 15 mar. 2021. 
SALES, J. C. A. et al. Proposal of methodology for spatial analysis applied to human development index in water basins. GEOJOURNAL, v. 84, p. 813-828, 2019. doi: https://doi.org/10.1007/s10708-018-9894-z

SCHNEIDER, F., COSTA, M. B. B. D. Diagnóstico socioeconômico, produtivo e ambiental dos agroecossistemas na micro bacia hidrográfica do rio Pirapora-município de Piedade/SP. Revista Brasileira de Agroecologia, v.8, n.1, p. 217-231, 2013.

SILVA, D. C. C. et al. Application of environmental indicators for water analysis in watershed. Revista Brasileira de Geografia Física, v. 10, p. 610-626, 2017. doi: https://doi.org/10.5935/1984-2295.20170039

SILVA, D. M. et al. Análise espacial da cobertura vegetal no centro urbano do município de Salto de Pirapora (SP). Caminhos de Geografia, v. 19, n. 68, p. 361371,2018. doi: https://doi.org/10.14393/RCG196824

SILVA, D. C. C. et al.. Análise da relação entre a distribuição espacial das morbidades por obesidade e hipertensão arterial para o estado de São Paulo, Brasil, de 2000 a 2010. Ciência e Saúde Coletiva, v. 19, p. 1709-1719, 2014. doi: https://doi.org/10.1590/1413-81232014196.15002013

SIMONETTI, V. C.; SILVA, D. C. C; ROSA, A. H. Análise da influência das atividades antrópicas sobre a qualidade da água da APA de Itupararanga (SP), Brasil. Geosul, v.34, n.72, p. 01-27, 2019. doi: https://doi.org/10.5007/1982-5153.2019v34n72p01

SPETH, G. et al. Conflitos de uso da terra em áreas de preservação permanente em Candelária (RS). Ciência e Natura, v.42, n.13, 2020. doi: https://doi.org/10.5902/2179460X40485

TOPODATA - Banco de Dados Geomorfométricos do Brasil. Disponível em: http://www.dsr.inpe.br/topodata/. Acesso em: 15 mar de 2021.

TV TEM. Sem água, moradores da zona rural de Piedade criam reservatório improvisado. G1 Sorocaba e Jundiaí. 7 out. 2020. Disponível em: https://g1.globo.com/sp/sorocaba-jundiai/noticia/2020/10/07/sem-agua-moradoresda-zona-rural-de-piedade-criam-reservatorio-improvisado.ghtml. Acesso em $15 / 03 / 2021$.

VALDERRAMA, L.; PAIVA, V. B.; MARÇO, P. H. Proposta experimental didática para o ensino de análise de componentes principais. Quim. Nova, v.39, n.2, p. 245-249, 2016. doi: $10.5935 / 0100-4042.20150166$

XIANG, R. et al. Temporal and spatial variation in water quality in the Three Gorges Reservoir from 1998 to 2021. Science of the Total Environment, v.768, p. 1-10, 2021. doi: $10.1016 /$ j.scitotenv.2020.144866

YIN, D. et al. Water quality related to Conservation Reserve Program (CRP) and cropland areas: Evidence from multi-temporal remote sensing. International Journal 
of Applied Earth Observations and Geoinformation, v.96, p. 1-9, 2021. doi: 10.1016/j.jag.2020.102272 